\title{
THE INFLUENCE OF X-IRRADIATION OF RABBIT SPERMATOZOA ON FERTILIZATION AND EARLY CLEAVAGE
}

\author{
J. M. BEDFORD* AND R. H. F. HUNTER \\ The Worcester Foundation for Experimental Biology, \\ Shrewsbury, Massachusetts 01545, U.S.A.
}

(Received 16th September 1967)

\begin{abstract}
Summary. Exposure of rabbit semen to X-irradiation did not reduce the fertilization rate until doses of $>25,000 \mathrm{r}$ were used, although motility was noticeably affected at 15,000 r. Evidence of a depressant effect of much lower doses of X-irradiation on the fertilizing ability of rabbit spermatozoa was obtained, however, by using a more sensitive system in which irradiated aliquots from an ejaculate were inseminated mixed together with an exactly equivalent volume of untreated semen from the same ejaculate. Under these competitive conditions the fertilizing ability of spermatozoa was found not to be affected by a dose of $10,000 \mathrm{r}$, but was significantly depressed $(P<0.01)$ by $15,000 \mathrm{r}$, as judged by an increase in the proportion of normally developing to retarded ova, recovered $50 \mathrm{hr}$ after an ovulation injection of HCG. It appears that this depressant effect is exerted at the site of fertilization rather than on sperm transport.

$\mathrm{X}$-irradiation of spermatozoa did not increase polyspermic or delayed fertilization, neither did irradiation have any significant effect on the formation of the male pronucleus. A dose response effect was seen at the time of the first cleavage division, for at $24 \mathrm{hr}$ the cleavage rate of control ova $(68.5 \%)$ was similar to that of ova fertilized by spermatozoa treated with $10,000 \mathrm{r}(68 \%)$, but only $33 \%$ of ova fertilized by spermatozoa treated with 20,000 to $25,000 \mathrm{r}$ had cleaved at this time compared with $78 \%$ of their controls. At 29 and $50 \mathrm{hr}$ several ova fertilized by irradiated spermatozoa remained at the pronuclear stage or at metaphase of the first cleavage division, and even at $50 \mathrm{hr}$ the great majority had only reached the 2-cell stage. Thus, although it is known that cleavage can occur in the absence of the male elements, the first cleavage division does not appear to follow activation of the egg automatically and independently since it has been shown that the state of the male elements introduced at fertilization can influence the rate and ultimate success of the changes which take place at this time.
\end{abstract}

* Present address : Department of Anatomy, Columbia College of Physicians and Surgeons, New York 10032. 


\section{INTRODUCTION}

In recent years there have been several studies of the effects of irradiation of rabbit spermatozoa on fertilization and subsequent embryonic development (Amoroso \& Parkes, 1947; Ghang, Hunt \& Romanoff, 1957; Nuzhdin \& Nizhnik, 1960). A dose of $1000 \mathrm{r}$ applied in vitro to spermatozoa is apparently sufficient to prevent development of viable young, but ova may be fertilized by spermatozoa subjected to much higher levels of $\gamma$ irradiation $(15,000 \mathrm{r}$, Nuzhdin \& Nizhnik, 1960; 65,000 r, Chang et al., 1957). Apart from an overall depressant effect on sperm motility at the level of $32,000 \mathrm{r}$, in general, it seems that the fertilizing ability of rabbit spermatozoa is relatively unaffected by $\gamma$ irradiation. Following exposure of spermatozoa to X-irradiation, Amoroso \& Parkes (1947), on the other hand, reported that delayed fertilization and polyspermy occurred commonly at levels of 1000 to 50,000 r. Since polyspermy occurs only rarely in the rabbit (Piko, 1961), the above observation might be held to imply that X-irradiation can modify elements on the sperm head which are of concern in the block to polyspermy; Austin \& Braden (1953) suggested that such polyspermy may have occurred during fertilization of ageing ova. In any event, the inference that X-irradiation of spermatozoa may affect the initial phases of fertilization, and its possible use as a method of induction of polyspermy, seemed to be of interest and to warrant further studies, which are described in the first part of this report.

During the course of the present studies it became apparent that sperm motility was somewhat depressed by levels of X-irradiation of $15,000 \mathrm{r}$ but that fertilization rate was not affected significantly until doses of $50,000 \mathrm{r}$, or more, were administered. An attempt has, therefore, been made to quantitate the effects of X-irradiation in a more objective manner, by allowing irradiated spermatozoa to compete with untreated spermatozoa in the female tract. The latter results are also presented in this paper.

\section{MATERIALS AND METHODS}

Ejaculates were collected from fertile rabbits with an artificial vagina. Within 5 min of collection an aliquot of the spermatozoa was irradiated using a Picker industrial X-ray unit linked to an automatic Radocon dosimeter. After irradiation at a dose rate of about $500 \mathrm{r} / \mathrm{min}(250 \mathrm{kV}, 15 \mathrm{~mA}$, total dose given in Table 1 ), irradiated and untreated sperm samples were inseminated separately into different female rabbits, per vaginam. On several occasions insemination was made directly into the ampulla of the Fallopian tube, in the manner described by Adams \& Chang (1962) - in this case, a direct comparison within one animal was made possible by the use of one oviduct for irradiated spermatozoa and the contralateral oviduct for the control sample. All females were given an ovulation injection of human chorionic gonadotrophin (HCG) at the time of insemination. The ova were flushed from the oviducts with Ringer solution at various times from 17 to $30 \mathrm{hr}$ after the ovulation injection. The ova were mounted on glass slides, examined in the fresh state with a phase microscope, and were then fixed in acetic alcohol. After 1 to $2 \mathrm{hr}$ of fixation, the ova were 
examined and then stained with lacmoid (Chang, 1952), following which it was usually possible, with oil immersion, to identify the tail of the fertilizing spermatozoon within the ooplasm (PI. 1, Fig. 1).

The effect of different levels of irradiation on the fertilizing ability of rabbit spermatozoa was studied in a more quantitative manner, using a technique in which irradiated spermatozoa and a comparable aliquot of untreated spermatozoa from the same ejaculate were mixed and inseminated into individual females. Thus two populations of spermatozoa would compete for fertilization of ova within any one female.

Ejaculates were divided immediately after collection and placed in embryo culture dishes covered with paraffin paper to prevent evaporation. One half of the ejaculate was irradiated at a rate of $500 \mathrm{r} / \mathrm{min}$ with a total dose which varied from 10,000 to $25,000 \mathrm{r}$; during this time the untreated sperm sample was kept under the same conditions as the irradiated sample. Following irradiation, aliquots were obtained from both the treated and untreated halves of the ejaculate, and were examined subjectively by an independent observer for assessment of sperm motility. Exactly equal volumes of irradiated and untreated semen were then mixed and the whole inseminated into the vagina of an oestrous rabbit, which also received an ovulation injection of HCG.

This type of mixed insemination was performed in four groups of ten females, the treated half of the inseminate having received a dose of $10,000,15,000$, 20,000 or $25,000 \mathrm{r}$. In another group of eight females, $0.025 \mathrm{ml}$ aliquots of 'mixed' semen $(20,000 \mathrm{r})$ were inseminated directly into the ampullae of the Fallopian tubes, in the manner described by Adams \& Chang (1962). Ova were collected from the inseminated females at $50 \mathrm{hr}$ after an ovulation injection, by which time most rabbit ova fertilized by normal spermatozoa have reached the 16-cell stage (Gregory, 1930). Preliminary experiments in this study made it clear that ova fertilized by spermatozoa previously subjected to $10,000 \mathrm{r}$ do not develop further than 3 to 4 cells at $50 \mathrm{hr}$, many remaining at the pronuclear or more commonly at the 2-cell stage. It has been assumed, therefore, that ova showing normal development, i.e. sixteen or more normal blastomeres with discrete nuclei, had been fertilized by normal non-irradiated spermatozoa, whereas those showing arrested development, i.e. pronuclear to 4-cell stage, often with fragmentation, had been fertilized by irradiated spermatozoa. In the latter group, the presence of perivitelline spermatozoa was taken as evidence of fertilization in eggs which had begun to fragment and in which the fertilizing sperm tail could not be found.

\section{RESULTS}

Effect of $X$-irradiation of spermatozoa on fertilization and early cleavage

Sperm motility was not significantly affected by doses of irradiation of less than $15,000 \mathrm{r}$. After exposure to $15,000 \mathrm{r}$, many, though not all ejaculates, underwent a definite reduction in the quality of their motility, viewed subjectively; at the 15,000 to 20,000 r dose level, a reduced vigour of movement and speed of progression of individual spermatozoa was seen, rather than a complete immobilization of a proportion of spermatozoa in the sample. The effect of

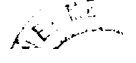


irradiation on motility became increasingly evident with higher dosage; at $50,000 \mathrm{r}$ only 10 to $15 \%$ of spermatozoa showed good progressive movement, though a majority of stationary spermatozoa in these samples still displayed vibratory tail movement. At 75,000 $\mathbf{r}$ most spermatozoa in six samples from different males were rendered motionless or showed only vibratory tail movements; though even at this level, a few spermatozoa in two samples were still motile and, in one instance, were able to fertilize a proportion of ova (Table I).

\section{TABLE 1}

ABNORMALITIES OF FERTILIZATION FOLLOWING X-IRRADIATION OF RABBIT SPERMATOZOA (OVA EXAMINED APPROX. 19 HR AFTER OVULATION INJECTION)

\begin{tabular}{c|c|c|c|c|c|c|c|c}
\hline \multirow{2}{*}{$\begin{array}{c}\text { Dose } \\
(r)\end{array}$} & $\begin{array}{c}\text { Total } \\
\text { ova } \\
\text { examined }\end{array}$ & $\begin{array}{c}\text { Ova } \\
\text { fert. } \\
(\%)\end{array}$ & $\begin{array}{c}\text { Delayed } \\
\text { fert. }\end{array}$ & $\begin{array}{c}\text { Poly- } \\
\text { spermic } \\
\text { fert. }\end{array}$ & $\begin{array}{c}\text { Three } \\
\text { pronuclei }\end{array}$ & $\begin{array}{c}\text { Fragmen- } \\
\text { tation } \\
\text { of } \\
\text { pronuclei }\end{array}$ & $\begin{array}{c}\text { Single } \\
\text { pronucleus }\end{array}$ & $\begin{array}{c}\text { Failure of } \\
\text { develomment } \\
\text { of male } \\
\text { pronucleus }\end{array}$ \\
\hline 750 & 44 & 100 & 1 & 0 & 0 & 0 & 0 & 0 \\
5,000 & 47 & 99 & 0 & 0 & 1 & 0 & 0 & 0 \\
10,000 & 50 & 99 & 0 & 0 & 0 & 0 & 1 & 1 \\
15,000 & 60 & 98 & 0 & 0 & 3 & 2 & 0 & 1 \\
$20-25,000$ & 33 & 94 & 0 & 0 & 1 & 2 & 1 & 0 \\
50,000 & 35 & 29 & 0 & 0 & 0 & 0 & 0 & 0 \\
75,000 & 32 & 18.5 & 0 & 0 & 0 & 0 & 0 & 0 \\
Total & 301 & 1 & - & 5 & 4 & 2 & 2 \\
\hline Control non- & 193 & 99 & & 2 & 1 & & 1 & \\
irradiated & 193 & & & & & & & \\
\hline
\end{tabular}

* Five females/group.

Exposure to $100,000 \mathrm{r}$ destroyed the capacity for progressive movement in all spermatozoa in samples collected from five different males. Throughout these experiments, in which fourteen different males were used, consistent differences were noticed between males in the ability of their ejaculated spermatozoa to withstand comparable doses of irradiation, particularly at the 15,000 and 20,000 r level of exposure.

\section{EXPLANATION OF PLATE 1}

FIG. 1. Part of a polyspermic pro-nuclear ovum (control) showing two sperm tails (arrowed) in the ooplasm; recovered $9 \mathrm{hr}$ after exposure to normal non-irradiated spermatozoa. The pronuclei are in a different plane of focus and are not visible. Note the split sperm tails seen commonly at this stage. Lacmoid; phase contrast, $\times 750$.

Frg. 2. Three pronuclei in an ovum fertilized by one spermatozoon that had been irradiated with 15,000 r. One sperm tail and one polar body were found in this ovum. Fixed in acetic alcohol but unstained; phase contrast, $\times 500$.

Figs. 3 and 4. Swelling sperm heads in the cytoplasm of ova which contained a normal female pronucleus about $9 \mathrm{hr}$ after ovulation. Ova exposed to spermatozoa irradiated with 10,000 and $15,000 \mathrm{r}$, respectively. Lacmoid; phase contrast, $\times 839$.

FIG. 5. Abnormal first cleavage spindle in an ovum fertilized by spermatozoon irradiated with $10,000 \mathrm{r}$; recovered about $18 \mathrm{hr}$ after ovulation. Lacmoid; phase contrast, $\times 625$.

Fig. 6. Ovum fertilized by spermatozoon irradiated with $15,000 \mathrm{r}$. This ovum contained only one sperm tail and two polar bodies; fragmenting female pronucleus is indicated. Fixed in acetic alcohol; unstained; phase contrast, $\times 500$. 
PIATE 1

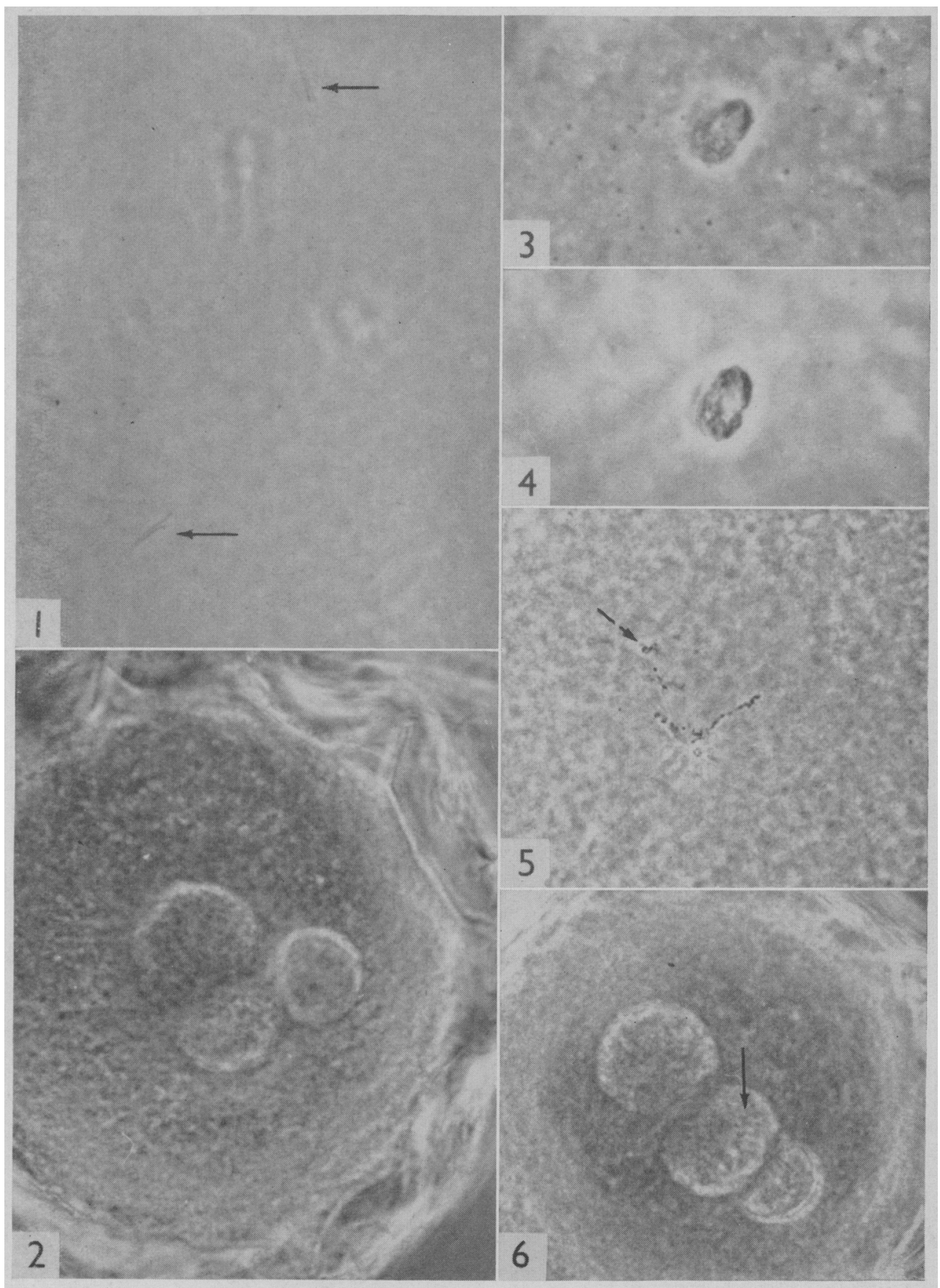

(Facing $p .52)$ 
The above observations on the motility of irradiated spermatozoa, broadly reflect the effects of X-irradiation on their fertilizing ability when inseminated alone (cf. mixed inseminations below, Table 3). It can be seen in Table 1 that no disturbance of the fertilization rate occurred after exposure of spermatozoa to 750 to $15,000 \mathrm{r}$. At 20,000 to $25,000 \mathrm{r}$, the only noticeable effect was a general reduction in the numbers of supernumerary and supplementary spermatozoa in association with the fertilized ova. At above 25,000 r, however, there was a clear decrease in fertilization rate. After exposure of spermatozoa to $50,000 \mathrm{r}, 29 \%$ of ova were fertilized and there was a further reduction to 18.5 at the 75,000 r level.

Although two definite instances of polyspermy were found in the control series (Pl. 1, Fig. 1), no polyspermy occurred in ova fertilized by irradiated spermatozoa, even when relatively large numbers were deposited directly into the ampulla of the oviduct. A total of five ova in the irradiated series contained three well-formed pronuclei (Pl. 1, Fig. 2), but each displayed only one polar body, and no more than one sperm tail could be detected in the ooplasm. In addition, four ova showing pronuclear fragmentation were observed (Pl. 1, Fig. 6 ). One instance of delayed fertilization was found in an ovum examined at about $9 \mathrm{hr}$ after ovulation in an animal inseminated with spermatozoa previously subjected to $750 \mathrm{r}$; in this particular ovum the second polar body had been only partially extruded, many spindle fibres remaining intact, and the slightly swollen sperm head was visible in the ooplasm; the remainder of the eggs from this animal had all reached the stage of pronuclear apposition. In two eggs fertilized by spermatozoa irradiated with 5,000 and $10,000 \mathrm{r}$, respectively, the swollen fertilizing sperm head had failed to develop into a pronucleus even at $10 \mathrm{hr}$ after ovulation (Pl. 1, Figs. 3 and 4). These ova could not be classified as examples of delayed fertilization since the centrally placed female pronucleus was well-formed. Two ova exposed to spermatozoa irradiated with 10,000 and $15,000 \mathrm{r}$, respectively, possessed only one centrally placed pronucleus as well as two polar bodies and in neither instance was a sperm head or tail detectable in the cytoplasm or in the perivitelline space.

Apart from these occasional examples, X-irradiation of spermatozoa had little effect on the rate of formation of the male pronucleus. For instance, in the one female in which six of ten eggs were fertilized by spermatozoa exposed to $75,000 \mathrm{r}$, all the fertilized ova showed male and female pronuclei of normal appearance in the early phase of syngamy, 10 to $11 \mathrm{hr}$ after ovulation. The influence of irradiation of the fertilizing spermatozoa first became consistently evident at the time of the first and second cleavage divisions (Table 2); for, although there was no appreciable difference, at $24 \mathrm{hr}$ after ovulation injection, in the percentage of ova cleaved in the control group $(68.5 \%)$ and in the group fertilized by spermatozoa exposed to $10,000 \mathrm{r}(68 \%)$, in the group fertilized by spermatozoa exposed to 20,000 to $25,000 \mathrm{r}$ only $33 \%$ of the fertilized eggs had cleaved at this time, as compared with $78 \%$ in the controls (Table 2). At both the 10,000 and 25,000 r levels, however, some of the 2-cell ova showed signs of cytoplasmic degeneration, typified particularly by extrusion of cytoplasm from the blastomeres and by nuclear fragmentation. At 28 to $29 \mathrm{hr}$ after mating all normally fertilized rabbit ova reach the 4-cell stage (Gregory, 1930), but of the 


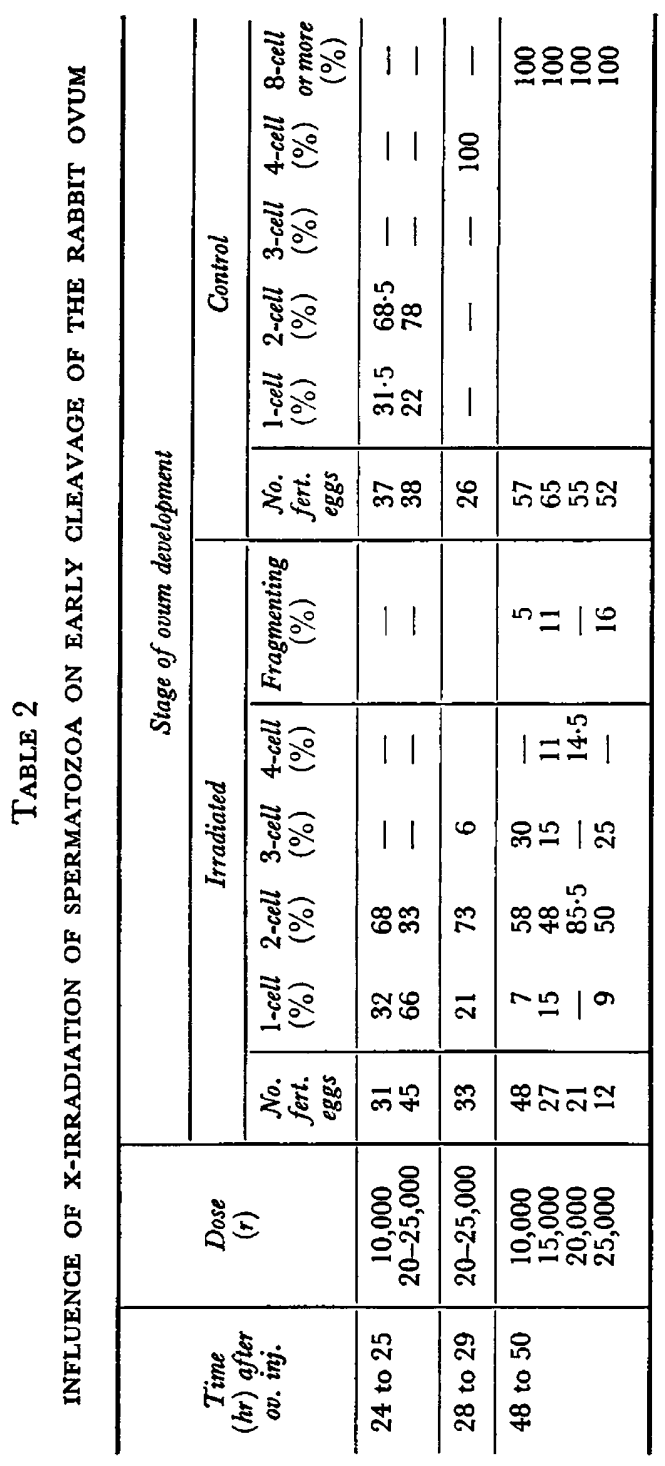


thirty-three $(97 \%)$ eggs fertilized by spermatozoa exposed to $25,000 \mathrm{r}$, only two $(6 \%)$ had divided into 3 cells by this time, the others remaining at the 1 - or 2-cell stage. From the eggs examined at 48 to $50 \mathrm{hr}$ (Table 3), it became clear that at 10,000 to $25,000 \mathrm{r}$ no further development would occur after the initial and occasionally the second cleavage.

TABLE 3

OVUM DEVELOPMENT 50 HR AFTER INSEMINATION OF EJAGULATES GONTAINING EQUAL NUMBERS OF NORMAL AND IRRADIATED SPERMATOZOA

\begin{tabular}{|c|c|c|c|c|}
\hline \multirow{3}{*}{$\begin{array}{l}\text { Irradiation } \\
\text { dose } \\
(r)\end{array}$} & \multicolumn{4}{|c|}{ Ova showing: } \\
\hline & \multicolumn{2}{|c|}{$\begin{array}{c}\text { Normal } \\
\text { development }\end{array}$} & \multirow{2}{*}{$\begin{array}{c}\text { Retarded } \\
\text { development } \\
\text { No. }\end{array}$} & \multirow{2}{*}{$\begin{array}{c}\text { Not } \\
\text { fertilized } \\
\text { No. }\end{array}$} \\
\hline & No. & $\%$ & & \\
\hline $\begin{array}{l}10,000 \dagger \\
15,000 \\
20,000 \\
25,000\end{array}$ & $\begin{array}{l}57 \\
65 \\
55 \\
55\end{array}$ & $\begin{array}{l}54 \\
70 \\
72 \\
81\end{array}$ & $\begin{array}{l}48 \\
27 * * \\
21 * * \\
12^{* * *}\end{array}$ & $\begin{array}{r}11 \\
4 \\
3 \\
10\end{array}$ \\
\hline $\begin{array}{l}\text { Tubal insemination } \ddagger \\
20,000\end{array}$ & 28 & 72 & 11 & 9 \\
\hline
\end{tabular}

Fertilizing ability of $X$-irradiated sperm in competition with untreated spermatozoa

Following mixed insemination of equal numbers of spermatozoa exposed to $10,000 \mathrm{r}$ and untreated spermatozoa from the same ejaculate, there was no significant difference in the percentage of normally developing ova $(54 \%)$ and degenerate or retarded fertilized ova $(46 \%)$ recovered from a group of ten females, $50 \mathrm{hr}$ after an ovulation injection. Subjection of one half of the inseminate to $15,000 \mathrm{r}$ (when effects on the quality of sperm motility also became apparent), significantly reduced the ability of irradiated spermatozoa to compete with the untreated spermatozoa $(P<0.01)$, only $30 \%$ of the fertilized ova being retarded in this group. The effects of the irradiation were increased at $25,000 \mathrm{r}$; following exposure to this dosage only $19 \%$ of ova fertilized were retarded at $50 \mathrm{hr}$ after ovulation injection $(P<0.001)$.

When aliquots of mixed semen were introduced directly into the oviducts of eight females after irradiation of one half of the sperm sample with $20,000 \mathrm{r}$, the state of the recovered ova was essentially the same as that of ova collected after vaginal insemination of such samples, that is to say only $28 \%$ of the ova fertilized were retarded in their development. This suggests that the influence of this order of irradiation on the fertilizing ability of rabbit semen is exerted mainly at the site of fertilization, rather than on transport of spermatozoa to this point.

\section{DISGUSSION}

Taken at their face value, the results obtained following insemination of irradiated spermatozoa alone (Table 1), appear to indicate that X-irradiation 
up to the level of $25,000 \mathrm{r}$ does not affect the fertilizing ability of ejaculated rabbit spermatozoa, and that depressant effects on fertility only occur above this level of irradiation. Indeed Amoroso \& Parkes (1947) obtained $96 \%$ activation of eggs in rabbits inseminated with spermatozoa irradiated with $25,000 \mathrm{r}$. It is clear from the results in Table 3, however, that while $10,000 \mathrm{r}$ had no significant effect on fertilizing ability, doses of either $15,000,20,000$ or 25,000 $\mathrm{r}$ render rabbit spermatozoa progressively less able to compete successfully within the female tract against the same number of normal untreated 'brother' spermatozoa. It is unlikely that the adverse influence of irradiation at $>10,000 \mathrm{r}$ is exerted mainly during spermatozoan transport through the female tract, since there was no difference in the results when mixed spermatozoan samples (at 20,000 r) were instilled directly into the ampulla of the Fallopian tube. This result makes it seem more likely that competition is exerted, and that the integrity of individual spermatozoa in the immediate vicinity of the ovum is most important.

It was interesting to find that the decreased ability to compete with normal spermatozoa became evident only when irradiation began to affect the motility of the spermatozoa (at 15,000 r), to the extent that an independent observer, using this criterion, could consistently identify the irradiated sperm sample. Furthermore, as progressive motility became more obviously depressed (at $25,000 \mathrm{r}$ ) so did the ability of the irradiated spermatozoa to compete for ova correspondingly deteriorate. It seems reasonable to incriminate the lowered spermatozoan motility as the factor responsible for the reduced ability of spermatozoa irradiated with $>10,000 \mathrm{r}$ to compete with their untreated counterparts, since this, and much higher dose levels of irradiation, apparently do not affect the organelles of the sperm head which facilitate its entry into the egg. These experiments, therefore, may also provide some direct experimental evidence for the well-established view that quality of sperm motility is one important index of semen fertility, although it must be remembered that poor sperm motility is not necessarily incompatible with fertility (Chang \& Thorsteinsson, 1958).

Neither delayed fertilization nor polyspermy were observed by other investigators during the course of similar studies using $\gamma$ irradiation (Chang et al., 1957; Nuzhdin \& Nizhnik, 1960). The present findings do not confirm the claim by Amoroso \& Parkes (1947) that polyspermy and delayed fertilization are a fairly common consequence of exposure of spermatozoa to X-irradiation at all levels from 1000 to $50,000 \mathrm{r}$. Fertilization was always monospermic after irradiation at levels from 750 to $75,000 \mathrm{r}$, and with one exception gave no indication of being delayed. Even in those animals in which a large number (about 1 million) of irradiated spermatozoa were instilled directly into the Fallopian tube, no polyspermy was observed, and the eggs fertilized by irradiated spermatozoa had all reached the same stage of pronuclear development as the control eggs recovered from the contralateral oviduct. Indeed Xirradiation seems to have no consistent effect on the early formation of the male pronucleus; in a total of 508 ova fertilized by irradiated spermatozoa only two sperm heads failed to swell into normal pronuclei (Pl. 1, Figs. 3 and 4) in eggs in which the female pronucleus had formed. In addition, only nine other eggs showed pronuclear abnormalities at the early stages, 1 or $2 \mathrm{hr}$ before the estimated time of the first cleavage division; fragmentation of the nuclei of the 
blastomeres was seen commonly, however, soon after the first cleavage had occurred.

The first cleavage division in rabbit ova can be induced parthenogenetically (Pincus, 1930). Following fertilization, however, the state of the male pronucleus can obviously sometimes act to inhibit this event, since irradiation of the fertilizing spermatozoa with 10,000 to $25,000 \mathrm{r}$ interfered with the formation and coordinated disjunction of the first cleavage spindle in several ova (Pl. 1, Fig. 5), which remained at the one-cell stage for up to $30 \mathrm{hr}$ after the normal time of the first cleavage division (Table 3). These results differ slightly from those of Chang et al. (1957), who found that the first cleavage division was inhibited by only the highest $(65,000 \mathrm{r})$ doses of $\gamma$ irradiation. It appears that during the events of the first cleavage division, there is also some degree of dose response, in that eggs fertilized by spermatozoa irradiated with $10,000 \mathrm{r}$ had achieved the same percentage cleavage $(68 \%)$ as the control ova $(68.5 \%) 24$ to $25 \mathrm{hr}$ after an ovulation injection of $\mathrm{HCG}$, whereas only $33 \%$ of ova fertilized by spermatozoa exposed to 20,000 to 25,000 $\mathrm{r}$ had cleaved at this time, compared with $78 \%$ of the control ova in this latter group. Thus 'activation' of the ovum by sperm entry does not necessarily trigger a chain of independent events which result inevitably in accomplishment of the first cleavage division, for the present results show that the stage of the male elements introduced at fertilization can sometimes influence the rate of cleavage and ultimate success of the changes which occur in the egg at this time.

\section{ACKNOWLEDGMENTS}

Thanks are due to Miss Stephanie Wallbanks for her technical help. This study was supported by National Institutes of Health Grant GM 14370.

\section{REFERENCES}

Adams, G. E. \& Chang, M. C. (1962) Capacitation of rabbit spermatozoa in the Fallopian tube and in the uterus. F. exp. Zool. 151, 159.

Amoroso, E. G. \& Parkes, A. S. (1947) Effects on embryonic development of X-irradiation of rabbit spermatozoa in vitro. Proc. R. Soc. B, 134, 57.

Austin, C. R. \& Braden, A. W. H. (1953) An investigation of polyspermy in the rat and rabbit. Aust. 7. biol. Sci. 6, 324 .

Chang, M. C. (1952) Fertilizability of rabbit ova and the effects of temperature in vitro on their subsesequent fertilization and activation in vivo. $\mathcal{F}$. exp. Zool. 121, 351.

Chang, M. G., Hunt, D. M. \& Romanoff, E. B. (1957) Effects of radiocobalt irradiation of rabbit spermatozoa in vitro on fertilization and early development. Anat. Rec. 129, 211.

Chang, M. C. \& Thorsteinsson, T. (1958) Effects of urine on motility and fertilizing capacity of rabbit spermatozoa. Fert. Steril. 9, 231.

Gregory, P. W. (1930) The early embryology of the rabbit. Contr. Embryol.Carneg. Inst., Washington, 21, 141 .

Nuzhdin, N. I. \& Nizhniк, C. V. (1960) The effects of irradiating the spermatozoa of rabbits with $\gamma$ rays on fertilization and on the early development of embryos. Proc. Acad. Sci. U.S.S.R. 134, No. 6.

Pixo, L. (1961) La polyspermie chez les animaux. Annls Biol. anim. Biochim. Biophys. 1, 324.

Pincus, G. (1930) Observations on the living eggs of the rabbit. Proc. R. Soc. B, 107, 32. 